\title{
Microwave as a rapid cooking method for beef tenderness evaluation
}

\author{
Douglas R. G. Silva ${ }^{1}$ (1) | Ludimila C. Fernandez $^{1}$ | Robledo A. Torres Filho ${ }^{2}$ | \\ Paulo R. Fontes ${ }^{1}$ | Alcinéia L. S. Ramos ${ }^{1}$ | Eduardo M. Ramos ${ }^{1}$
}

${ }^{1}$ Departamento de Ciência dos Alimentos, Universidade Federal de Lavras (UFLA), Lavras, Minas Gerais, Brazil

${ }^{2}$ Instituto de Ciências Exatas e Tecnológicas, Universidade Federal de Viçosa (UFV), Florestal, Minas Gerais, Brazil

\section{Correspondence}

Douglas R. G. Silva, Departamento de Ciência dos Alimentos, Universidade Federal de Lavras (UFLA), P.O. Box 3037, Lavras, Minas Gerais 37200-000, Brazil. Email: d-guimaraes2@hotmail.com

\section{Funding information}

Fundação de Amparo à Pesquisa do Estado de Minas Gerais; Conselho Nacional de Desenvolvimento Científico e Tecnológico; FAPEMIG; Coordenação de Aperfeiçoamento de Pessoal de Nível Superior

\begin{abstract}
Semitendinosus (ST) muscle steaks were grouped according to three locations (proximal, middle, and distal end), grilled to endpoint temperature of $71 \mathrm{C}$ or cooked for $20,30,40,50$, or $60 \mathrm{~s}$ in a microwave oven $(\mathrm{Mw})$. The location did not affect $(p>.05)$ the cooking loss $(\mathrm{CL})$ or shear force (SF) values. The CL increased $(p<.05)$ with longer microwave cooking times, but only the Mw40 samples did not differ $(p>.05)$ from the grill samples. None of the microwaves' SF values were different $(p>.05)$ from the grill values, with treatments Mw30 to Mw50 showing moderate repeatability $(R=0.51-0.60)$ and $M w 30$ and Mw60 showing higher correlations $(r>.71)$ with grill values. Cooking beef strips with a microwave is a potential method for tenderness evaluation, but requires additional study to evaluate and optimize this application in different muscles and for comparison to sensorial data.
\end{abstract}

\section{Practical applications}

The work was intended to evaluate the possibility of using a microwave oven for cooking meat to be used in objective measurement protocols for meat tenderness and to optimize the conditions for this purpose. The use of a standardized microwave procedure allows a dramatic reduction in analysis time and may reduce error variance due to nonuniform cooking procedures.

\section{KEYWORDS}

clam-shell grill, microwave oven, protocol analysis, shear force

\section{1 | INTRODUCTION}

Instrumental methods for measuring shear force (SF) have been used extensively for meat tenderness evaluations. Among these methods, the Warner-Bratzler single-blade shear test has been the most widely used method for assessing meat tenderness due to its accuracy and repeatability, producing tenderness values that correlate well to the tenderness ratings of consumers (Destefanis, Brugiapaglia, Barge, \& Dal Molin, 2008; Miller, Carr, Ramsey, Crockett, \& Hoover, 2001). However, the difficulty of standardizing tenderness evaluation is one of the main problems related to the beef quality (Silva, de Moura, Ramos, \& Ramos, 2017). The implementation of a standardized protocol, which is imperative for accurate and repeatable measurements (Ramos \& Gomide, 2007), depends on whether the cooking methods provide

This article was published on AA publication on: 20 November 2017. reproducible, consistent results. The cooking parameters (the method, rate, degree of doneness) can have a significant impact on meat tenderness, and thus, these methods need to be standardized to the fullest extent possible.

Following the attempt to identify and eliminate sources of variation in the measurement of meat palatability traits, Wheeler, Shackelford, and Koohmaraie (1998) concluded that the largest remaining source of error variance was the cooking process. There are different cooking methods available to use in meat research, and the methods preferred by a particular institution may differ based on cost, space allowance, ease of use, and effectiveness for research (Yancey, Wharton, \& Apple, 2011). However, as observed in the literature, a majority of research institutions use AMSA guidelines, which recommend cooking meat to $71 \mathrm{C}$ in open-hearth electric broilers or oven-broilers (AMSA, 2015), although the consistency of these cooking methods has been questioned (Wheeler et al., 1998). 
Wheeler et al. (1998) identified electric belt grills, devices that cook both sides of a steak simultaneously as it moves on a conveyer, as a more precise, repeatable, and rapid alternative to electric broilers. The conduction heating of belt grilling was popularized by its use in the MARC Beef Tenderness Classification System (Shackelford, Wheeler, \& Koohmaraie, 1999). However, this equipment may be cost prohibitive, and it is not a practical option for most research institutions because it is available in only some countries or must be imported, often requiring special facilities. The clam-shell grill has become an alternative to the belt grill because it is less expensive and its conduction heating system has been found to have repeatability around 0.87 (Kerth, Blair-Kerth, \& Jones, 2003; Mckenna, King, \& Savell, 2003), greater than 0.70 as suggested in the AMSA protocol (AMSA, 2015).

Several studies have examined the effects of cooking methods as well as the end-point temperature on the SF values and the repeatability of SF measurements (Kerth et al., 2003; Lawrence, King, Obuz, Yancey, \& Dikeman, 2001; McKenna et al., 2003; Obuz, Dikemana, \& Loughin, 2003; Yancey et al., 2011). However, the use of microwave cooking for meat tenderness evaluation, as proposed by Hostetler and Dutson (1978), has been neglected, despite its enormous potential for use in these protocols due to its low cost, convenience, and speed of execution.

The results of the SF tests of microwaved samples that were obtained by Hostetler and Dutson (1978) were greater (25\%) than those of samples cooked with an electrical broiler, but the microwave tenderness values were significantly correlated with the electrical broilers values and the consumer tenderness ratings. Although these results indicate the feasibility of using microwaves as a cooking method for tenderness protocols, the effects of different cooking times were not evaluated by these authors, and the procedures reported have not been standardized, especially with regard to the quantity of the cooked samples. Therefore, the objective of this research was to compare the effects of meat cooking in a clam-shell grill versus cooking in a microwave oven for different times on the magnitude, variance, and repeatability of cooking loss (CL) and of SF values.

\section{2 | MATERIALS AND METHODS}

\section{1 | Samples}

Five eye of round (Semitendinosus [ST] muscle) beef cuts were purchased from a large commercial processor. Beef cuts, obtained from male Nellore animals, had various postmortem aging times. At the Laboratory of Technology of Meat and Meat Products (LabCarnes), in the Department of Food Science of the Federal University of Lavras, each piece was vacuum-packaged, frozen (in freezer at $-20 \mathrm{C}$ ), and stored until further processing.

Each frozen ST was sliced using a band saw to yield nine steaks (2.54-cm thick). The steaks were removed from the thickest portion of each muscle and were identified sequentially starting at the proximal end. The steaks were separated into three groups (Figure 1): three proximal-end steaks (Location A), three middle steaks (Location B), and three distal-end steaks (Location C). Each group of steaks was then

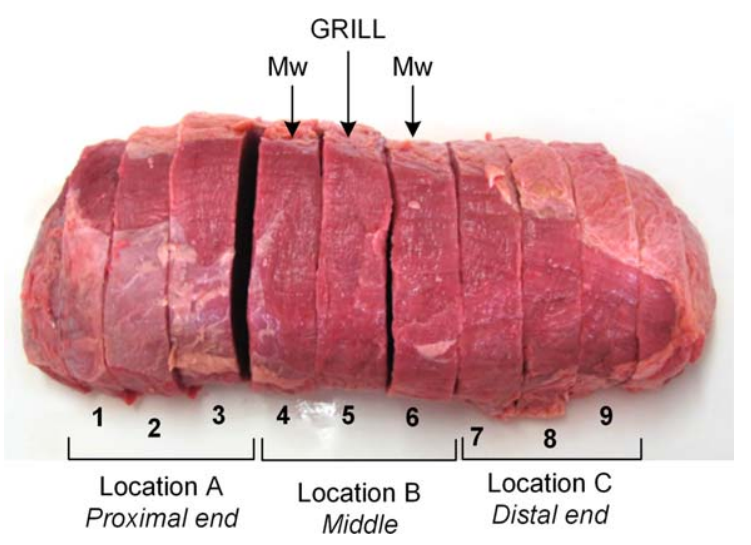

FIGURE 1 Sampling locations for microwave cooking (Mw) and clam-shell grilling (grill) treatments for cooking loss and shear force evaluations

assigned to one of the two cooking methods: the second (Location A), fifth (Location B), and eighth (Location C) steaks were cooked on the clam-shell grill; and the first/third (Location A), fourth/sixth (Location B), and seventh/ninth (Location C) steaks were cooked in the microwave oven.

\section{2 | Clam-shell grilling}

The steaks were thawed ( $4 \mathrm{C}$ for $24 \mathrm{hr}$ ) and trimmed of external fat and epimysial connective tissue before cooking. All steaks were weighed before and after cooking to determine CL.

The steaks were placed on a Grill Britânia (model Mega, Curitiba, PR, Brazil) clam-shell-style contact grill with a "ribbed" surface for conduction cooking both sides of the steak simultaneously. The grill was preheated for $10 \mathrm{~min}(\sim 160 \mathrm{C})$ and the steaks cooked until a $71 \mathrm{C}$ internal temperature was attained. The temperature was monitored with thermocouple wires that were inserted into the geometric center of each steak.

To assess SF, cooked steaks were allowed to cool at room temperature for approximately $1 \mathrm{hr}$. Six square cores $(1.0 \times 1.0 \times 2.5 \mathrm{~cm})$ that were parallel to the length of the muscle fiber orientation were removed (using a sample model box) to be sheared following the Warner-Bratzler square shear force (WBsSF) protocol.

\section{3 | Microwave cooking (Mw)}

The frozen steaks $(\sim 2 \mathrm{C})$ were trimmed of external fat and approximately $2.0-\mathrm{cm}$ of the side edges of the frozen steak was removed. To get homogeneous samples for microwave cooking, cores were obtained from steaks still frozen. Using a sample model box, five pieces of approximately $5.00 \mathrm{~cm}$-long and $1.00 \mathrm{~cm}$-width were obtained. From each piece that was still frozen, $1.0 \mathrm{~cm}$ sections parallel to the muscle fibers were cut using another sample model box to obtain five square cores of $1.0 \times 1.0 \times 2.5 \mathrm{~cm}$. For each steak evaluated, 25 samples were obtained, providing 50 samples by location group.

Ten random samples were immediately placed in a container that had been lined with a paper towel, which was then used to cover the 
meat for microwave cooking (Electrolux, model MEF33, $2450 \mathrm{MHz}$, Manaus, AM, Brazil) for different times $(20,30,40,50$, or $60 \mathrm{~s})$ at maximum power (800 W).

The sample groups were weighed before and after cooking to determine $\mathrm{CL}$. The cooked samples were allowed to cool at room temperature for approximately $15 \mathrm{~min}$ and were then sheared following the WBsSF protocol.

\section{4 | Warner-Bratzler square shear force}

For SF measurements, we use the WBsSF protocol described by Silva et al. (2015). According to these authors, the WBsSF method was faster, technically simpler, and more accurate, as it allows for easier recognition of muscle fiber orientation, thereby ensuring that samples were taken parallel to muscle fiber orientation. The WBsSF measures the amount of force required to shear across whole muscle fibers using a square cross-section samples $(1.0 \times 1.0 \times 2.5 \mathrm{~cm}$ cuboid cores) instead of round cross-section samples $(1.27 \mathrm{~cm}$ diameter and $2.5 \mathrm{~cm}$ length cylinder cores) as proposed in the AMSA guidelines for WarnerBratzler shear force (WBSF) protocol. Silva et al. (2015) observed a strong and significant linear relationship between WBSF and WBsSF values for beef and pork samples, suggesting WBsSF as an alternative method to standardize the core sampling for SF measurements. Recently, Silva et al. (2017) reported that the use of WBsSF method provide a greater repeatability and sensitivity for detecting tenderness differences than WBSF method, indicating an additional improvement in SF measurement.

Each square cross-section core was sheared once at the center, perpendicular to the fiber orientation, with a Warner-Bratzler type shear (3.05 mm-thickness) attachment using an electronic testing machine (model TA.XT plus, Stable Micro Systems, Godalming, United Kingdom). The crosshead speed was set at $200 \mathrm{~mm} /$ $\min$.

\section{5 | Statistical analysis}

To reduce variation arising from differences due to muscle tenderness (animal's age, aging time, and other factors), the data were arranged in a randomized block design, where each muscle composed a single block. The effects of the treatments, the location of the steak, and their interaction were evaluated by analysis of variance (ANOVA). Depending on the significance $(p<.05)$ of the ANOVA, the effects of the treatment were tested by a Dunnett test for comparison with the reference group (clam-shell grilling), and the effects of location and interaction were tested by the Tukey test. Correlation coefficients $(r)$ for $\mathrm{CL}$ and SF values were calculated using the Pearson procedure to determine relationships among clam-shell grill and microwave oven treatments. Correlations were considered significant at $p<.05$.

Variance components $\left(\sigma^{2}\right)$ of animal, location, and error were estimated with the REML option of the VARCOMP procedures of SAS System for Windows 9.2 (Statistical Analysis System-SAS Institute Inc., Cary, NC). For each muscle, repeatability (R) was calculated using Equation 1, as described by Shackelford, Wheeler, and Koohmaraie (1997).

$$
\mathrm{R}=\frac{\sigma_{\text {animal }}^{2}+\sigma_{\text {location }}^{2}}{\sigma_{\text {animal }}^{2}+\sigma_{\text {location }}^{2}+\sigma_{\text {error }}^{2}}
$$

\section{3 | RESULTS AND DISCUSSION}

\section{1 | Effect of location}

There were no interaction effects $(p>.05)$ among the steak location (proximal, medial, or distal end) or the cooking treatments (grill or microwave) for the CL or SF values. In addition, the beef location did not affect $(p>.05)$ the $C L$ or SF values (Table 1). These results differed from those reported by Shackelford et al. (1997), who found a lower

TABLE 1 Effect of location and the descriptive statistics for cooking loss and shear force values of Semitendinosus steaks cooked with a clam-shell grill or with a microwave oven ( $\mathrm{Mw})$ for different times (20,30,40,50, and $60 \mathrm{~s})$

\begin{tabular}{|c|c|c|c|c|c|c|c|}
\hline \multirow[b]{2}{*}{ Treatments } & \multicolumn{3}{|c|}{ Location } & \multirow[b]{2}{*}{ Mean } & \multirow[b]{2}{*}{$S D$} & \multirow[b]{2}{*}{ Minimum } & \multirow[b]{2}{*}{ Maximum } \\
\hline & A & B & C & & & & \\
\hline \multicolumn{8}{|c|}{ Cooking loss (\%) } \\
\hline Mw20 & 18.22 & 8.89 & 10.24 & $12.45^{\mathrm{a}}$ & 8.65 & 4.61 & 35.45 \\
\hline Mw30 & 24.58 & 23.95 & 24.21 & $24.25^{\mathrm{a}}$ & 6.38 & 10.62 & 34.85 \\
\hline Mw40 & 34.98 & 32.61 & 33.41 & 33.67 & 3.30 & 28.47 & 38.55 \\
\hline \multicolumn{8}{|c|}{ Shear force (kg) } \\
\hline Grill & 5.94 & 6.20 & 6.56 & 6.23 & 1.38 & 3.44 & 7.84 \\
\hline Mw20 & 6.10 & 6.15 & 6.08 & 6.11 & 0.79 & 4.92 & 7.39 \\
\hline Mw30 & 5.77 & 5.95 & 5.87 & 5.86 & 0.77 & 4.62 & 7.28 \\
\hline Mw40 & 5.75 & 6.50 & 5.99 & 6.08 & 0.90 & 4.48 & 7.47 \\
\hline Mw50 & 5.68 & 6.10 & 6.40 & 6.06 & 0.86 & 4.81 & 7.28 \\
\hline
\end{tabular}

Location: $\mathrm{A}=$ proximal-end steaks; $\mathrm{B}=$ middle steaks; $\mathrm{C}=$ distal-end steaks.

$S D=$ standard deviation.

${ }^{\mathrm{a}}$ Mean values significantly different $(p<.05)$ from the reference group (grill) by the Dunnett test. 
$\mathrm{CL}$ and SF value and a greater sensory panel tenderness rating for steaks located in the distal end of the ST muscle cooked with a belt grill. However, the cause of the location variation on the tenderness of ST muscle could not be determined by the authors. Lawrence et al. (2001), when evaluating the effects of different cooking methods on different muscles, observed that the variation in $\mathrm{CL}$ for the ST muscle was affected by the location only in the samples cooked on a belt-grill (with a temperature setting of 93C) and for samples cooked with the forced-air convection methods. Concerning SF values, none of the tested methods assessed by these authors was affected by location.

\section{2 | Cooking loss}

The $\mathrm{CL}$ increased $(p<.05)$ with higher microwave cooking times and only samples cooked for $40 \mathrm{~s}$ (Mw40) did not differ ( $p>.05$ ) from grill cooked samples (Table 1). According to Honikel and Hamm (1994), the main factors affecting $\mathrm{CL}$ are the endpoint temperature and speed of cooking. Microwaved roasts took less time to reach endpoint temperatures compared to those cooked by conventional methods. Thus, these factors combined may explain the differences in the observed values due to the different microwave cooking times. The relative increase in $\mathrm{CL}$ became more pronounced at endpoint temperatures higher than 60C (Bouton \& Harris, 1972; Obuz, Dikeman, Grobbel, Stephens, \& Loughin, 2004). This trend of increasing CL might be attributed to shrinkage of the muscle fibers and collagen, as discussed below.

Greater CLs most frequently are attributed to greater evaporative losses (Carpenter, Abraham, \& King, 1968). However, drip losses during cooking were greater for microwaved steaks compared with those cooked in conventional ovens, while evaporation losses are the opposite (Howat, Gros, Mcmillin, Saxton, \& Hoskins, 1987; Payton \& Baldwin, 1985). These previous findings can be explained by the lack of crust formation in steaks cooked in microwave ovens and is consistent with what was observed in our experiment. In the conventional method, the superheated $(\sim 160 \mathrm{C})$ grid of the clam-shell grill in contact with the sample surface promotes rapid protein denaturation, forming a crust that seals the surface and reduces the amount of moisture and lipid that is able to escape from the steak (Kerth et al., 2003; Wheeler et al., 1998). Moreover, in our experiment, the samples cooked in the microwave were cut prior to cooking. Water escaped from the muscle primarily by the "drip channels," formed along the length of the muscle fiber, that guide the water from the extracellular space to the meat surface (Huff-Lonergan \& Lonergan, 2005). Therefore, a mechanical disruption of the muscle fibers by cutting could favors water loss by these drip channels during the cooking process.

\section{3 | Shear force}

Although differences in CL have been observed, the SF values of samples from microwave treatments were not different $(p>.05)$ from those of grilled sample (Table 1). The sample SF average was equal to $6.07 \pm 0.93 \mathrm{~kg}$.

Longer microwave cooking times imply higher values of endpoint temperature, producing an expected increase in SF values (Obuz et al.,
2004; Palka \& Daun, 1999; Yancey et al., 2011). The increase in meat toughness with a temperature increase is due to heat denaturation of the myofibrillar proteins and thermal shrinkage of the connective tissue, causing a greater compression of the myofibril structure (i.e., decrease in sarcomere length with consequent longitudinal shrinkage of muscle fibers) and exudation of moisture (as observed in CL, Table 1) (Bouton \& Harris, 1972; Christensen, Purslow, \& Larsen, 2000; Harris \& Shorthose, 1988; Obuz et al., 2004; Ramos \& Gomide, 2007). However, at greater temperatures (above $55 \mathrm{C}$ ), the progressive loss of the crimp structure, shrinkage of the collagen fibers, and increased solubilization of collagen occurs, which decreases the load-bearing ability and thereby the tensile breaking strength of the connective tissue (Lewis \& Purslow, 1989).

The increase in collagen solubility with the increase in cooking temperature and time is associated with an increase in tenderness due to the conversion of collagen to gelatin by cooking (Lawrie, 2006). In addition, Palka and Daun (1999) observed maxima in the texture profile analysis (TPA) parameters (i.e., hardness, cohesiveness, and chewiness) in the range of 70-80C, with the tenderizing effect of temperatures higher than $80 \mathrm{C}$, which is most likely caused by the gelatinization of collagen in the meat. They reported changes in the microstructure of cooked beef, with visible granulation between the muscle fibers appearing in the range of 70-100C. The same damage was observed by Yarmand and Homayouni (2010) in the microstructure of Semimembranous (SM) muscle from domestic microwave heating, which resulted in more shrinkage and breakdown in the SM muscle than did roasting. According to these authors, domestic microwave heating caused little hydrolysis of the connective tissue, but caused more damage to the structure of both the connective tissue and the myofibrillar elements than did roasting. The rapid increase of heat in the microwave thermal process causes not only shrinkage and structural disruption but also granulation and separation of some parts of the muscle fiber, which affects the muscle tenderness.

Although the endpoint temperature from microwave heating was not measured in our experiment, it was observed that the strips were being cooked "very well done" (dry and brown throughout) in the microwave oven for times greater than $30 \mathrm{~s}$ (Figure 2), which suggests an end point temperature greater than 77C (NLSMB, 1979). Hostetler and Dutson (1978) reported that the endpoint temperature of strips $(1.3 \times 1.3 \times 2.5 \mathrm{~cm}$ long) cooked in a microwave oven for $30 \mathrm{~s}$ was most likely $85 \mathrm{C}$ or higher. Due to relatively high collagen contents of the ST muscle, the solubilization of collagen and damage to fiber microstructure could be counterbalanced by an increased myofibrillar toughening. Together, these antagonistic effects of microwave cooking may explain why no differences were observed between the treatments with regard to SF values.

\section{4 | Variance components, repeatability, and correlation coefficients}

Variance components, repeatability, and correlation coefficients (compared to clam-shell grilling) of CL and SF are reported in Table 2. Repeatability was calculated as the proportion of the total 

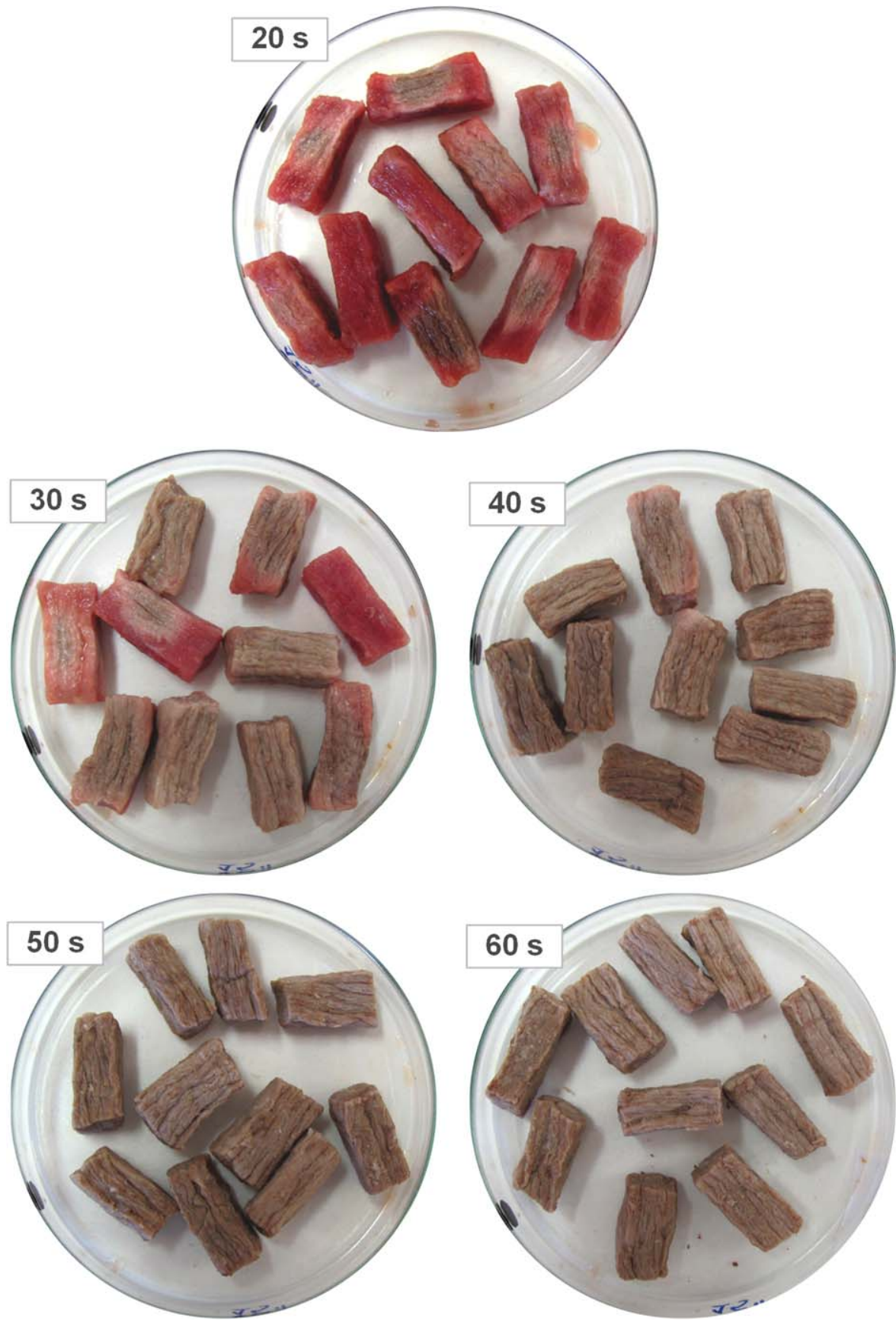

FIGURE 2 Degree of steaks doneness cooked in microwave oven at different times

variance that can be attributed to the sample and, therefore, is an indication of measurement precision. For both $\mathrm{CL}$ and SF, the variation was not affected by location, which contradicts data from Shackelford et al. (1997), who found that the animal and location had a high impact on the SF and a small but still significant impact on CL of STs.

The repeatability of $C L$ values was high $(R=0.89$ and 0.90$)$ for 50 and $60 \mathrm{~s}$ of microwave cooking (Mw50 and Mw60, respectively). Shackelford et al. (1997) observed that $\mathrm{CL}$ values were moderately repeatable $(R=0.61)$ for ST muscles cooked in a belt grill, whereas Lawrence et al. (2001) observed differences in repeatability values ( $R=0.24-0.60)$ for the ST CL depending on the cooking method.
It is recognized that the evaluation of $\mathrm{CL}$ is not easily reproducible, and the results reported in the literature for different cooking methods of Longissimus dorsi did not achieve repeatability values greater than 0.70 as set forth by AMSA (2015). In addition, the repeatability of SF varies with the type of muscle, being less for tougher muscles. Thus, for the ST muscle, the high repeatability of SF values of samples cooked in the microwave oven for 30-50 s $(R=0.50-0.60$; Table 2$)$ was similar to the 0.56 value reported by Shackelford et al. (1997) for belt grill-cooked samples as well as to the 0.67 value reported by Lawrence et al. (2001) for electric broiler cooked samples. However, the repeatability of the SF values for ST cooked in a belt grill observed by Lawrence et al. (2001) were much 
TABLE 2 Variance components, repeatability, and correlation coefficients ( $r$ ) of cooking loss and shear force values of Semitendinosus steaks cooked with a clam-shell grill or with a microwave oven (Mw) for different times (20,30, 40, 50, and $60 \mathrm{~s})$

\begin{tabular}{|c|c|c|c|c|c|c|c|c|c|c|}
\hline \multirow[b]{2}{*}{ Treatments } & \multicolumn{4}{|c|}{ Variance component } & \multicolumn{3}{|c|}{ Percentage of total variance } & \multirow[b]{2}{*}{ Repeatability } & \multicolumn{2}{|c|}{ Correlation $^{a}$} \\
\hline & Animal & Location & Error & Total & Animal & Location & Error & & $r$ & $p$ Value \\
\hline \multicolumn{11}{|c|}{ Cooking loss (\%) } \\
\hline Mw20 & 27.40 & 15.06 & 41.49 & 83.95 & 33 & 18 & 49 & 0.51 & .18 & .577 \\
\hline Mw30 & 15.92 & 0.00 & 27.69 & 43.61 & 37 & 0 & 63 & 0.37 & .28 & .385 \\
\hline Mw40 & 3.99 & 0.00 & 7.61 & 11.6 & 34 & 0 & 66 & 0.34 & .54 & .072 \\
\hline Mw50 & 16.83 & 0.00 & 2.00 & 18.83 & 89 & 0 & 11 & 0.89 & .49 & .129 \\
\hline \multicolumn{11}{|c|}{ Shear force (kg) } \\
\hline Grill & 2.15 & 0.08 & 0.08 & 2.31 & 93 & 3 & 3 & 0.97 & - & - \\
\hline Mw20 & 0.22 & 0.00 & 0.45 & 0.67 & 33 & 0 & 67 & 0.32 & .62 & .032 \\
\hline Mw30 & 0.33 & 0.00 & 0.32 & 0.65 & 51 & 0 & 49 & 0.51 & .71 & .010 \\
\hline Mw40 & 0.49 & 0.05 & 0.37 & 0.91 & 54 & 5 & 41 & 0.60 & .51 & .091 \\
\hline Mw50 & 0.39 & 0.03 & 0.39 & 0.81 & 48 & 4 & 48 & 0.52 & .61 & .037 \\
\hline
\end{tabular}

${ }^{a}$ Correlation of each microwave treatment versus the grill treatment. Significant probabilities $(p<.05)$ were placed in bold.

higher $(R=0.83$ and 0.86$)$ than the values reported by Shackelford et al. (1997) and our microwave values. In contrast, the repeatability of SF values from clam-shell-grilled ST samples observed in this experiment $(R=0.97)$ was greater than all those reported above, including some determined for Longissimus dorsi (Table 3), whereas the repeatability with microwave cooking treatments are similar or slightly below some of these values. Therefore, although the SF repeatability was lower than clam-shell-grill cooking, the microwave cooking had a good repeatability compared with other cooking methods, supporting potential use as cooking method in meat tenderness protocols.

TABLE 3 Repeatability of cooking loss and shear force values of Longissimus dorsi beef samples cooked by different methods (endpoint temperature $\sim 71 \mathrm{C}$ )

\begin{tabular}{|llll} 
Cooking method & $\begin{array}{l}\text { Cooking } \\
\text { loss }\end{array}$ & $\begin{array}{l}\text { Shear } \\
\text { force }\end{array}$ & Reference \\
\hline Clam-shell grill & 0.15 & 0.88 & Kerth et al. (2003) \\
\hline Clam-shell grill & 0.23 & 0.86 & McKenna et al. (2003) \\
\hline Clam-shell grill & 0.38 & $0.85^{\mathrm{a}}$ & Silva et al. (2017) \\
\hline Clam-shell grill & 0.21 & 0.59 & Yancey et al. (2011) \\
\hline Belt grill (163C) & 0.58 & 0.85 & Wheeler et al. (1998) \\
\hline Belt grill (163C) & 0.12 & 0.83 & Lawrence et al. (2001) \\
\hline Electric broiler & 0.00 & 0.41 & McKenna et al. (2003) \\
\hline Electric broiler & 0.05 & 0.75 & Yancey et al. (2011) \\
\hline Electric broiler & 0.23 & 0.64 & Wheeler et al. (1998) \\
\hline Electric broiler & 0.44 & 0.63 & Lawrence et al. (2001) \\
\hline Gas oven (163C) & 0.18 & 0.88 & Kerth et al. (2003) \\
\hline Gas oven (163C) & 0.00 & 0.63 & Yancey et al. (2011) \\
\hline Gas oven (163C) & 0.13 & 0.50 & Lawrence et al. (2001) \\
\hline
\end{tabular}

${ }^{a}$ With Warner-Bratzler square shear force.
Although the $\mathrm{CL}$ values of Mw40 cooked samples did not differ $(p>.05)$ from those of grilled samples, none of the correlation coefficients for microwave $C L$ versus grilled $C L$ were significant $(p>.05)$. On the contrary, although the SF values of samples from all microwave treatments did not differ $(p>.05)$ from those of the grilled samples, only the Mw40 treatment showed no significant correlation $(p>.05)$ with the clam-shell grill treatment (Table 2). This behavior can, perhaps, be justified by the lack of difference in CL between Mw40 and Grill samples. In this situation, the effect of water loss on shrinkage of the myofibrillar structure is not different in both treatments and the only effects on SF are due to the temperature and type of cooking effects on the myofibrillar structure and the connective tissue, as previously discussed in the section "Shear force."

The correlation coefficients of the SF values from Mw20, Mw30, Mw50, and Mw60 cooked samples $(r>.61)$ versus the SF values of grilled samples were in agreement with Hostetler and Dutson (1978), who reported a significant correlation between the values of SF for microwave cooked (for $30 \mathrm{~s}$ ) versus Farberware-broiled samples of Longissimus dorsi muscles $(r=.94)$ or versus conventional oven (hot air)-cooked SM muscles ( $r=.69$ ).

The use of microwave cooking was moderately satisfactory for evaluating CL. The CL from Mw40 samples did not differ $(p>.05)$ from the grilled samples, so there was no significant correlation $(p>.05)$ between microwave cooking and grill cooking. Furthermore, only the Mw50 and Mw60 treatments showed high repeatability $(R>0.89)$. However, the use of microwave cooking can be considered appropriate for tenderness evaluation because the SF values of microwaved samples did not differ $(p>.05)$ from those of grilled samples. Moreover, the repeatability of microwave cooking treatments showed values close to those reported for ST in the literature. The Mw40 treatment showed no significant correlation $(p>.05)$ with grill cooking SF values, which may be due to the low variation observed in the sample SF values (Table 1). Among microwave treatments, cooking beef ST strips for $40 \mathrm{~s}$ seems to be an acceptable method for instrumental tenderness evaluation. 
However, repeatability should be taken into consideration, and correlations of the microwave treatments used in this experiment may have been underestimated due to the method used for sample preparation. While obtaining the meat strips, some samples underwent a partial defrosting before being microwaved. The response of ice to microwaves is different from that of liquid water, as ice permits deeper microwave penetration but has a lower rate of microwave absorption and, therefore, of heat development (Yarmand \& Homayouni, 2010). Therefore, a partially frozen strip may have areas with different degrees of doneness after microwave cooking, increasing sample variability. This phenomenon was clearly observed in microwaved samples for 20 and $30 \mathrm{~s}$ (Figure 2). Thus, measures to prevent the samples from defrosting, even partially, should be taken while obtaining strips for microwave cooking.

\section{4 | CONCLUSION}

Although the data presented in this study were limited by sample size, they demonstrate, the potential for using microwave cooking as a rapid way for cooking meat to be used in research for tenderness determinations by instrumental SF protocol. Additional evaluation is necessary across more samples (of steaks), as well as checks for correlation directly with the sensory analysis. It is also important to evaluate and optimize this application in different muscles, especially in Longissimus dorsi, the main muscle evaluated in tenderness protocols.

\section{ETHICAL STATEMENTS}

Conflict of Interest: The authors declare that they do not have any conflict of interest.

Ethical Review: This study does not involve human or animal testing. Informed Consent: Written informed consent was obtained from all study participants.

\section{ACKNOWLEDGMENTS}

The authors would like to thank the Fundação de Amparo à Pesquisa do Estado de Minas Gerais (FAPEMIG) and the Conselho Nacional de Desenvolvimento Científico e Tecnológico (CNPq) for their financial support and to FAPEMIG and the Coordenação de Aperfeiçoamento de Pessoal de Nível Superior (CAPES) for the scholarship granting to the first (master's degree/FAPEMIG) and fourth (post-doctoral PNPD, CAPES/UFLA) authors.

\section{ORCID}

Douglas R. G. Silva iD http://orcid.org/0000-0003-4573-8378

\section{REFERENCES}

American Meat Science Association (AMSA). (2015). Research guidelines for cookery, sensory evaluation, and instrumental tenderness measurements of meat (2nd ed.). Champaign: Author.

Bouton, P. E., \& Harris, P. V. (1972). The effects of cooking temperature and time on some mechanical properties of meat. Journal of Food Science, 37, 140-144.
Carpenter, Z. L., Abraham, H. C., \& King, G. T. (1968). Tenderness and cooking loss of beef and pork. I. Relative effects of microwave cooking, deep-fat frying, and oven-broiling. Journal of the American Dietetic Association, 53, 353-356.

Christensen, M., Purslow, P. P., \& Larsen, L. M. (2000). The effects of cooking temperature on mechanical properties of whole meat, single muscle fibers and perimysial connective tissue. Meat Science, 55, 301-307.

Destefanis, G., Brugiapaglia, A., Barge, M. T., \& Dal Molin, E. (2008). Relationship between beef consumer tenderness perception and Warner-Bratzler shear force. Meat Science, 78, 153-156.

Harris, P. V., \& Shorthose, W. R. (1988). Meat texture. In R. Lawrie (Ed.), Developments in meat science (pp. 245-296). London: Elsevier Applied Science.

Honikel, K. O., \& Hamm, R. (1994). Measurement of water-holding capacity and juiciness. In A.M. Pearson \& T.R. Dutson (Eds.), Quality attributes and their measurement in meat, poultry and fish products (pp. 125-161). New York: Blackie Academic \& Professional.

Hostetler, R. L., \& Dutson, T. R. (1978). Investigation of a rapid method for meat tenderness evaluation using microwave cookery. Journal of Animal Science, 43, 304-306.

Howat, P. M., Gros, J. N., Mcmillin, K. W., Saxton, A. M., \& Hoskins, F. (1987). Comparison of beef blade roasts cooked by microwave, microwave convection and conventional oven. Journal of Microwave Power, 22, 95-98.

Huff-Lonergan, E., \& Lonergan, S. M. (2005). Mechanisms of waterholding capacity of meat: The role of postmortem biochemical and structural change. Meat Science, 71, 194-204.

Kerth, C. R., Blair-Kerth, L. K., \& Jones, W. R. (2003). Warner-Bratzler shear force repeatability in beef longissimus steaks cooked with a convection oven, broiler, or clam-shell grill. Journal of Food Science, $68,668-670$

Lawrence, T. E., King, D. A., Obuz, E., Yancey, E. J., \& Dikeman, M. E. (2001). Evaluation of electric belt-grill, forced-air convection oven, and electric broiler cookery methods for beef tenderness research. Meat Science, 58, 239-246.

Lawrie, R. A. (2006). Lawrie's meat science (7th ed.). Cambridge, United Kingdom: Woodhead Publishing.

Lewis, G. J., \& Purslow, P. P. (1989). The strength and stiffness of perimysial connective tissue isolated from cooked beef muscle. Meat Science, 26, 255-269.

Mckenna, D. R., King, D. A., \& Savell, J. W. (2003). Comparison of clamshell cookers and electric broilers and their effects on cooking traits and repeatability of Warner-Bratzler shear force values. Meat Science, 66, 225-229.

Miller, M. F., Carr, M. A., Ramsey, C. B., Crockett, K. L., \& Hoover, L. C. (2001). Consumer threshold for establishing the value of beef tenderness. Journal of Animal Science, 79, 3062-3068.

NLSMB. (1979). The meat board beef steak color guide. Chicago, IL: National Live Stock and Meat Board.

Obuz, E., Dikeman, M. E., Grobbel, J. P., Stephens, J. W., \& Loughin, T. M. (2004). Beef longissimus lumborum, biceps femoris, and deep pectoralis Warner-Bratzler shear force is affected differently by endpoint temperature, cooking method, and USDA quality grade. Meat Science, 68, 243-248.

Obuz, E., Dikemana, M. E., \& Loughin, T. M. (2003). Effects of cooking method, reheating, holding time, and holding temperature on beef longissimus lumborum and biceps femoris tenderness. Meat Science, 65, 841-851.

Palka, K., \& Daun, H. (1999). Changes in texture, cooking losses, and myofibrillar structure of bovine $\mathrm{M}$. semitendinosus during heating. Meat Science, 54, 237-243. 
Payton, J., \& Baldwin, R. E. (1985). Comparison of top round steaks cooked by microwave convection, forced-air convection and conventional ovens. Journal of Microwave Power, 20, 255-259.

Ramos, E. M., \& Gomide, L. A. M. (2007). Avaliação da qualidade de carnes: Fundamentos e metodologias. Viçosa, Brazil: Editora UFV.

Shackelford, S. D., Wheeler, T. L., \& Koohmaraie, M. (1997). Repeatability of tenderness measurements in beef round muscles. Journal of Animal Science, 75, 2411-2416.

Shackelford, S. D., Wheeler, T. L., \& Koohmaraie, M. (1999). Tenderness classification of beef. II: Design and analysis of a system to measure beef longissimus shear force under commercial processing conditions. Journal of Animal Science, 77, 1474-1481.

Silva, D. R. G., de Moura, A. P. R., Ramos, A. L. S., \& Ramos, E. M. (2017). Comparison of Warner-Bratzler shear force values between round and square cross-section cores for assessment of beef Longissimus tenderness. Meat Science, 125, 102-105.

Silva, D. R. G., Torres Filho, R. A., Cazedey, H. P., Fontes, P. R., Ramos, A. L. S., \& Ramos, E. M. (2015). Comparison of Warner-Bratzler shear force values between round and square cross-section cores from cooked beef and pork Longissimus muscle. Meat Science, 103, 1-6.
Wheeler, T. L., Shackelford, S. D., \& Koohmaraie, M. (1998). Cooking and palatability traits of beef longissimus steaks cooked with a belt grill or an open hearth electric broiler. Journal of Animal Science, 76, 2805-2810.

Yancey, J. W. S., Wharton, M. D., \& Apple, J. K. (2011). Cookery method and end-point temperature can affect the Warner-Bratzler shear force, cooking loss, and internal cooked color of beef longissimus steaks. Meat Science, 88, 1-7.

Yarmand, M. S., \& Homayouni, A. (2010). Quality and microstructural changes in goat meat during heat treatment. Meat Science, 86, 451-455.

How to cite this article: Silva DRG, Fernandez LC, Torres Filho RA, Fontes PR, Ramos ALS, Ramos EM. Microwave as a rapid cooking method for beef tenderness evaluation. J Texture Stud. 2017;00:1-8. https://doi.org/10.1111/jtxs.12312 